\title{
Overexpression of $\beta$-Catenin Induces Cisplatin Resistance in Oral Squamous Cell Carcinoma
}

\author{
Long Li, ${ }^{1,2}$ Hai-Chao Liu, ${ }^{1,2}$ Cheng Wang, ${ }^{1,2}$ Xiqiang Liu, ${ }^{1,2}$ Feng-Chun Hu, ${ }^{1,2}$ Nan Xie,, \\ Lanhai Lï, ${ }^{2}$ Xiaohua Chen, ${ }^{2,3}$ and Hong-Zhang Huang ${ }^{1,2}$ \\ ${ }^{1}$ Department of Oral and Maxillofacial Surgery, Guanghua School and Hospital of Stomatology, Sun Yat-sen University, \\ Guangzhou 510055, China \\ ${ }^{2}$ Guangdong Key Laboratory of Stomatology, Sun Yat-sen University, Guangzhou 510074, China \\ ${ }^{3}$ Department of Oral Pathology, Guanghua School and Hospital of Stomatology, Sun Yat-sen University, \\ Guangzhou 510055, China
}

Correspondence should be addressed to Xiaohua Chen; xiaohua_312@163.com

and Hong-Zhang Huang; hongzhanghuang@126.com

Received 2 May 2016; Accepted 22 June 2016

Academic Editor: Antonello Merlino

Copyright (c) 2016 Long Li et al. This is an open access article distributed under the Creative Commons Attribution License, which permits unrestricted use, distribution, and reproduction in any medium, provided the original work is properly cited.

\begin{abstract}
Abnormal expression of $\beta$-catenin contributes to tumor development, progression, and metastasis in various cancers. However, little is known about the relationship between abnormal expression of $\beta$-catenin and cisplatin chemotherapy in oral squamous cell carcinoma (OSCC). The present study aimed to investigate the effect of $\beta$-catenin on OSCC cisplatin resistance and evaluated the drug susceptibility of stable cell lines with $\beta$-catenin knockin and knockdown. In this study, we found that higher expression level of $\beta$-catenin can be observed in CDDP-treated cell lines as compared with the control group. Furthermore, the expression levels of $\beta$-catenin increased in both a concentration- and time-dependent manner with the cisplatin treatment. More importantly, the nuclear translocation of $\beta$-catenin could also be observed by confocal microscope analysis. Stable cell lines with CTNNB1 knockin and knockdown were established to further investigate the potential role and mechanism of $\beta$-catenin in the chemoresistance of OSCC in vitro and in vivo. Our findings indicated that overexpression of $\beta$-catenin promoted cisplatin resistance in OSCC in vitro and in vivo. We confirmed that GSK-3 $\beta$, C-myc, Bcl-2, P-gp, and MRP-1 were involved in $\beta$-catenin-mediated drug resistance. Our findings indicate that the $\mathrm{Wnt} / \beta$-catenin signaling pathway may play important roles in cisplatin resistance in OSCC.
\end{abstract}

\section{Introduction}

Head and neck cancer is the sixth most common cancer worldwide with approximately 600,000 new cases per year [1]. Between $40 \%$ and $60 \%$ of the patients with locally advanced head and neck cancer will relapse [2,3], and nearly $50 \%$ of patients will die due to tumor-related complications $[4,5]$. The vast majority of the head and neck cancers are oral squamous cell carcinomas (OSCC). The incidence of OSCC has been rapidly increasing in Asia [6] and more than $12 \%$ of these cases occur in China [7]. Furthermore, the number of deaths of patients with tongue squamous cell carcinoma has increased by $11 \%$ during the past 5 years $[8,9]$. Conventional treatments for OSCC include surgery, radiotherapy, and chemotherapy. Although treatments have greatly improved in the past few years, the survival rate in patients with advanced OSCC treated by surgery alone or radiotherapy alone is still poor. Compared with a single modality treatment, a combination of surgery, radiotherapy, and chemotherapy increases the 5 -year overall survival rate by $6.5 \%$ [10]. Patients receiving chemotherapy had better survival rates than those not receiving chemotherapy [11, 12]. Chemotherapy has several benefits, especially for patients being considered for organ-preserving treatment, including reduced metastasis, improved local regional control, longer survival, and preservation of organ function [13]. Chemotherapy in conjunction with surgery or radiotherapy was more effective in advanced OSCC $[14,15]$. However, the effectiveness of chemotherapy is limited by chemoresistance to certain anticancer drugs [16]. Cisplatin is a first-generation anticancer compound 
that has been widely used to treat OSCC for many years. However, cisplatin used in the chemotherapy for OSCC often fails because of the rapid development of both inherent and acquired chemoresistance, which limits its application [17]. The molecular mechanisms of cisplatin drug resistance in OSCC remain largely unknown.

$\beta$-catenin, coded by CTNNB1, is an important adhesion molecule and a key regulator in the Wnt signaling pathway, which has many important functional roles including the maintenance of epithelial stability, growth, and differentiation [18]. The Wnt/ $\beta$-catenin pathway was reported to be associated with chemoresistance in epithelial ovarian cancer $[19,20]$. Furthermore, $\beta$-catenin has been demonstrated to be associated with drug resistance in different types of human cancers $[21,22]$. However, little is known about the relationship between drug resistance and $\beta$-catenin in OSCC.

In our previous study, we demonstrated that P-glycoprotein (P-gp), Bcl-2, MDR, and multidrug resistanceassociated proteins-1 (MRP-1) were involved in cisplatin resistance in tongue squamous cell carcinoma [23]. We confirmed that there was abnormal expression of $\beta$-catenin in tissue samples from patients who had received cisplatin chemotherapy compared with tissue specimens from patient without chemotherapy. We found that overexpression of $\beta$-catenin could promote $\mathrm{P}$-gp, Bcl-2, MDR, and MRP1 expressions that enhanced cisplatin resistance in OSCC cell lines. These findings provided important clues to the mechanisms involved in OSCC drug resistance. In addition, we found an increase in the expression levels of $\beta$-catenin in the OSCC cell lines treated with cisplatin compared with the controls. Therefore, we hypothesize that $\beta$-catenin may play a crucial role in the development of drug resistance in OSCC. In the present study, we investigated the role of $\beta$-catenin in the development of chemoresistance in OSCC cell lines.

\section{Materials and Methods}

2.1. Cell Culture and Treatment. Two human OSCC cell lines (SCC-15 and SCC-25) were selected for analysis. SCC15 and SCC-25 cells (American Type Culture Collection, USA) were cultured in DMEM-Ham's F12 medium (Gibco, USA) with $400 \mathrm{ng} / \mathrm{mL}$ hydrocortisone (Sigma, USA), $1 \%$ penicillin/streptomycin (Gibco, USA), and 10\% FBS (Hyclone Laboratories Inc., UT, USA). All cells were incubated in a humidified atmosphere containing $5 \% \mathrm{CO}_{2}$ at $37^{\circ} \mathrm{C}$ and then subcultured by trypsinization (Trypsin-EDTA, Lonza). For the analysis of the expression levels of $\beta$-catenin, OSCC cells were treated with cisplatin $(0.5$ and $2 \mu \mathrm{g} / \mathrm{mL})$ for $24 \mathrm{~h}$. The control cells were treated with regular media.

2.2. Establishment of Stable OSCC Cell Lines with CTNNB1 Knockin and Knockdown. We used recombinant lentiviruses, pGLV3-GFP-CTNNB1-shRNA, pGLV3-GFP-NC, pGLV5-GFP-CTNNB1, and pGLV5-GFP-NC (Vipotion Biotechnology, Guangzhou, China). The amplification primer sequence for CTNNB1: CTNNB1-F: 5'-ATGGCTA-CTCAAGCTGATTTGAT-3', CTNNB1-R: $5^{\prime}$-TTACAGGTCAGTATCAAACCA-GG-3' . The siRNA primer sequences are
siRNA-homo-1302, 5' -AGGTGCTAT-CTGTCTGCTCTA-3', and NC siRNA, $5^{\prime}$-TTCTCCGAACGTGTCACGTTTC-3'.

Stable SCC-25 cell lines with CTNNB1 knockin and knockdown were established via infection of the high titer lentiviral particles (GenePharma, Shanghai, China), which was cotransfected into 293T cells and purified according to the manufacturer's instructions. The supernatant containing infectious lentiviruses was harvested for transductions. The isolated transfectants were further selected by culture in $2 \mathrm{mg} / \mathrm{mL}$ Puromycin (Life Technologies, USA) and confirmed by proliferation assay. The transfection efficiency was detected by PCR and Western blotting. Stable expressing cells with CTNNB1 knockin and knockdown were used in the subsequent study.

2.3. Cell Apoptosis Assay. For the apoptosis assay, cells with stable CTNNB1 overexpression and knockdown were treated with $2 \mu \mathrm{g} / \mathrm{mL}$ cisplatin (Sigma, USA) for $24 \mathrm{~h}$ following the manufacturer's protocol. Cells were collected and stained with Annexin V PE/7AAD apoptosis kit (LiankeBio, Hangzhou, China) and detected by flow cytometry (FACSCalibur, BD Biosciences, USA). Cells that were negative with propidium iodide (PI) and Annexin V are considered healthy, cells are considered apoptotic with PI negative and Annexin $\mathrm{V}$ positive, and cells that are positive to both PI and Annexin $\mathrm{V}$ are considered necrotic. The experiments were repeated at least three times.

2.4. Assessment of Cell Viability and Proliferation. Cells with stable CTNNB1 overexpression and knockdown were seeded at a density of $5.0 \times 10^{3}$ cells per well for cell the viability assay and $2.0 \times 10^{3}$ cells per well for the proliferation assay and were cultured accordingly. For the cell viability assay, cells were treated with cisplatin $(0,0.5,1,2,4,8$, and $16 \mu \mathrm{g} / \mathrm{mL})$ for $24 \mathrm{~h}$. Proliferation assay was performed on days 1 to 7 . Cell growth was assessed using the Cell Counting Kit 8 assay (CCK-8; Beyotime Biotechnology, China) according to the manufacturer's protocol. After appropriate incubation, $10 \mu \mathrm{L}$ of CCK-8 solution was added per well and incubated at $37^{\circ} \mathrm{C}$ for 1 hour. The absorbance of each well was measured at $450 \mathrm{~nm}$ using a microplate reader (Multiskan MS; Thermo Fisher Scientific, USA). Growth curve was drawn to assess the effect of $\beta$-catenin on proliferation. The cytotoxicity of cisplatin in the OSCC cell lines was quantified by the inhibitory concentration $50 \%\left(\mathrm{IC}_{50}\right)$, which was calculated as previously described [24]. Each experiment was repeated at least three times.

2.5. Confocal Microscopy. SCC- 15 and SCC- 25 cells $\left(5.0 \times 10^{3}\right.$ cells) were seeded on a glass-bottom dish (Corning, USA) and cultured with cisplatin $(1 \mu \mathrm{g} / \mathrm{mL})$ for 24,48 , and $72 \mathrm{~h}$ and with different concentrations of cisplatin $(0,1,2$, and $4 \mu \mathrm{g} / \mathrm{mL}$ ) for $24 \mathrm{~h}$. Regular media was used as the control. Primary antibodies to $\beta$-catenin (8480S, $1: 100$, Cell Signaling Technology) were added to the cells and incubated at $4^{\circ} \mathrm{C}$ overnight. After washing, FITC-conjugated goat anti-rabbit IgG (1:1000, Cell Signaling Technology) was added and incubated at room temperature in the dark for $2 \mathrm{~h}$ and then 
TABLE 1: Sequences of oligonucleotides used in RT-PCR analysis.

\begin{tabular}{lccc}
\hline Gene & Accession number & Forward primer & Reverse primer \\
\hline$\beta$-catenin & NM_001098209 & CATCTACACAGTTTGATGCTGCT & GCAGTTTTGTCAGTTCAGGGA \\
GSK-3 $\beta$ & NM_001146156 & GGCAGCATGAAAGTTAGCAGA & GGCGACCAGTTCTCCTGAATC \\
Bcl-2 & NM_000633 & GGTGGGGTCATGTGTGTGG & CGGTTCAGGTACTCAGTCATCC \\
MRP-1 & NM_004996 & GTCGGGGCATATTCCTGGC & CTGAAGACTGAACTCCCTTCCT \\
MDR-1 & NM_000927 & GGGAGCTTAACACCCGACTTA & GCCAAAATCACAAGGGTTAGCTT \\
GAPDH & NM_001256799 & TCCAAAATCAAGTGGGGCGA & AAATGAGCCCCAGCCTTCTC \\
siRNA3-homo-1302 & & AGGTGCTATCTGTCTGCTCTA \\
Negative & & TTCTCCGAACGTGTCACGTTTC \\
\hline
\end{tabular}

covered with Prolong ${ }^{\circledR}$ Gold Antifade Reagent and DAPI for 10 minutes at room temperature (\#8961, 4,6-diamidino2-phenylindole; Sigma). Confocal images were taken with a Zeiss LSM 510 laser scanning confocal microscope (Carl Zeiss, Jena, Germany).

2.6. Reverse Transcription-Quantitative PCR (RT-qPCR). Total RNA was isolated from the OSCC cell lines using TriPure (Roche Molecular Biochemicals, Mannheim, Germany) according to the manufacturer's instructions. $1 \mu \mathrm{g}$ of total RNA for one $20 \mu \mathrm{L}$ reaction volume was reverse transcribed to cDNA using the transcriptor first-strand cDNA synthesis kit (Roche Molecular Biochemicals, Mannheim, Germany) according to the manufacturer's instructions. The first-strand cDNA synthesis was performed by the use of Applied Biosystems ${ }^{\circledR}$ Veriti PCR (Veriti, Thermo Fisher, USA). qPCR was performed using a LightCycler ${ }^{\circledR} 480$ SYBR Green I Master (Roche Diagnostics, Germany), following thermal cycling parameters: preincubation at $95^{\circ} \mathrm{C}$ for $5 \mathrm{~min}$, followed by 40 cycles of amplification $\left(95^{\circ} \mathrm{C}\right.$ for $10 \mathrm{~s}, 60^{\circ} \mathrm{C}$ for $20 \mathrm{~s}$, and $72^{\circ} \mathrm{C}$ for $\left.30 \mathrm{~s}\right)$, melting curve $\left(95^{\circ} \mathrm{C}\right.$ for $5 \mathrm{~s}$, $65^{\circ} \mathrm{C}$ for $60 \mathrm{~s}$, and $\left.97^{\circ} \mathrm{C}-\right)$, and cooling $\left(40^{\circ} \mathrm{C}\right.$ for $\left.10 \mathrm{~s}\right)$. Expression levels were analyzed using the $\Delta \Delta \mathrm{Cq}$ method [25], and gene expression was normalized to the internal control, glyceraldehyde 3-phosphate dehydrogenase. The primers are shown in Table 1. All samples were analyzed in triplicate.

2.7. Western Blotting. SCC-25, SCC-15, and the cells with $\beta$-catenin knockin and knockdown were lysed with RIPA buffer (Beyotime Biotechnology, China) and nuclear fractions of SCC-25 and SCC-15 cells were isolated by the use of Cellytic ${ }^{\mathrm{TM}}$ Nuclear $^{\mathrm{TM}}$ Extraction Kit (NXTRACT, Sigma, USA) to detect the cellular localization of $\beta$-catenin. Protein concentrations were quantified by the use of BCA Protein Assay Kit (Beyotime Biotechnology, China). Western blotting was performed according to standard protocols. 40 $60 \mu \mathrm{g}$ total protein extract was separated by SDS-PAGE on a $8 \%-10 \%$ gradient gel and then transferred onto a PVDF membrane (Millipore, Billerica, MA, USA) for 1 to $2 \mathrm{~h}$. The membrane was blocked in $5 \%$ nonfat dry milk at room temperature for 1 hour and incubated overnight at $4^{\circ} \mathrm{C}$ with the following antibodies: anti-MRP-1 (ab32574,
1:1000, Abcam), anti-P-gp (ab3366, 1:1000, Abcam), antiC-myc (5605S, 1:1000, Cell Signaling Technology), antiGSK-3 $\beta$ (9315S, 1:1000, Cell Signaling Technology), antiBcl-2 (2870S, 1:1000, Cell Signaling Technology), anti- $\beta$ catenin (9582S, 1:1000, Cell Signaling Technology), anti$\beta$-actin (4970S, 1:1000, Cell Signaling Technology), and anti-histone (9715, 1:1000, Cell Signaling Technology). The secondary antibody was horseradish peroxidase-conjugated anti-mouse (7076P2, 1:1000, Cell Signaling Technology) and anti-rabbit (7074S, 1:1000, Cell Signaling Technology). The membrane was then incubated with HRP-linked secondary antibodies $(1: 1000)$ at room temperature for $2 \mathrm{~h}$. Membranes were analyzed by chemiluminescence using an ECL system (Invitrogen, China) and bands were visualized using FluorChem Q (Alpha Innotech, Sunnyvale, CA, USA). All experiments were repeated at least three times.

2.8. Animal Study. Male BALB/c-nu nude mice ( $n=24 ; 3-4$ weeks old) from the Laboratory Animal Center of Sun Yatsen University were used in the study. Mice were maintained in a temperature controlled on a 12 -h light-dark cycle, with free access to food and water at $22^{\circ} \mathrm{C}$. For the overexpression of $\beta$-catenin, a total of $1 \times 10^{7}$ SCC- 25 cells with CTNNB1 knockin were injected in the left posterior flanks, and the right anterior flanks were used as the negative control. For the decreased expression of $\beta$-catenin, a total of $1 \times 10^{7}$ SCC-25 cells with CTNNB1 knockdown were injected in the left posterior flanks, and the right anterior flanks were used as the negative control. The tumor size was measured using Vernier calipers. Tumor volume was calculated by the following formula: volume $=0.5 \times$ length $\times$ width $^{2}$ (length: longest diameter in $\mathrm{mm}$, width: the shortest diameter in $\mathrm{mm}$ ). When the tumor had grown to an average volume of $100 \mathrm{~mm}^{3}$ (after about 14 days), the mice were given an injection of cisplatin $(4 \mathrm{mg} / \mathrm{kg})$ through the tail vein at 3-day intervals for five times. The tumor size was monitored every 3 days after inoculation. The animals were then sacrificed under anesthesia with an overdose of pentobarbital sodium $(50 \mathrm{mg} / \mathrm{kg}$, 1063180500, Merck, Germany) and individual tumor volumes were calculated. All animal procedures were approved by the Sun Yat-sen University Medical Experimental Animal Care Commission. 


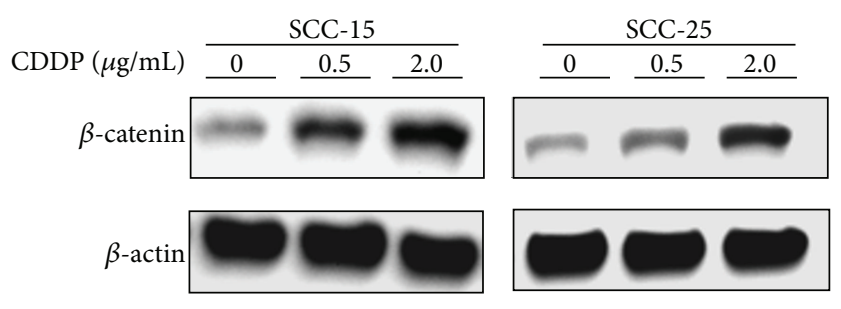

(a)
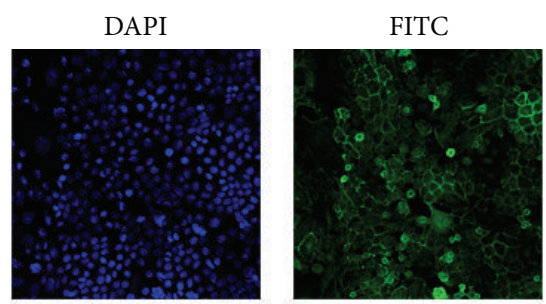

(A)
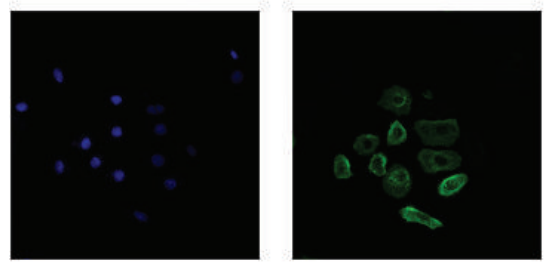

(B)
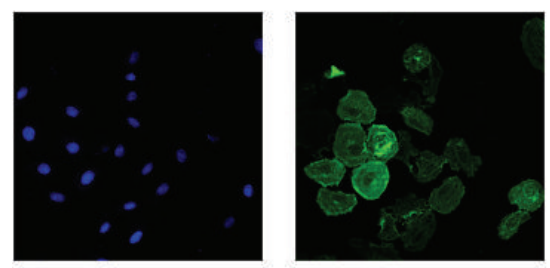

(C)
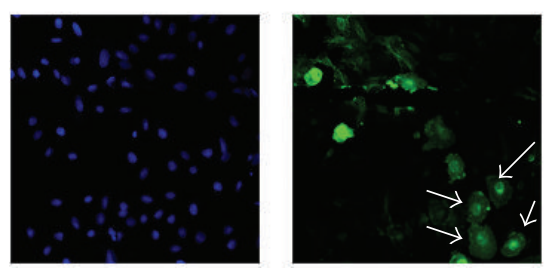

(D)
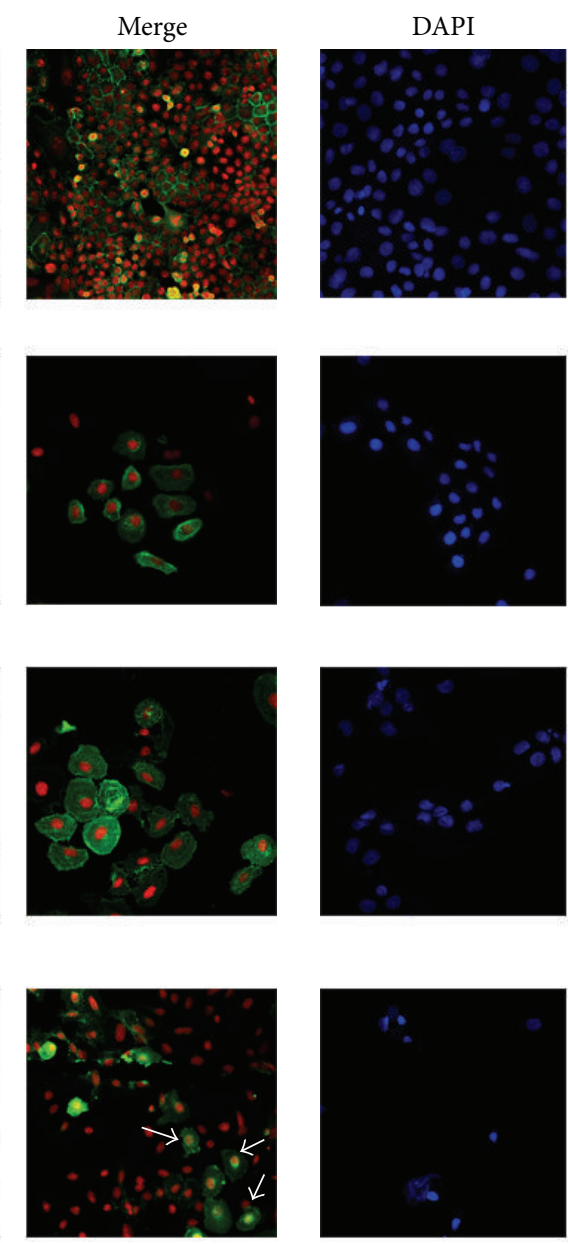

(b)
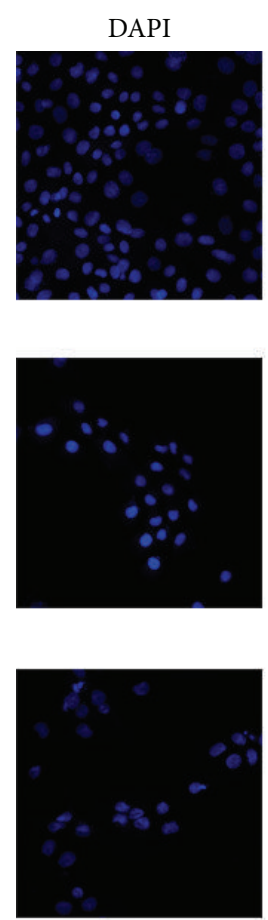

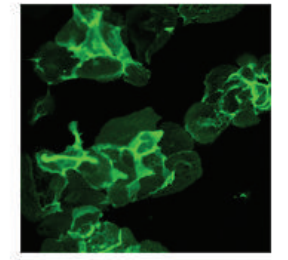

(G)

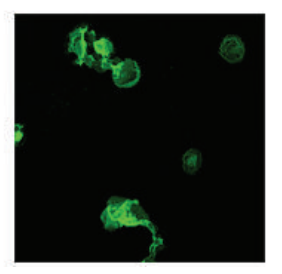

(H)
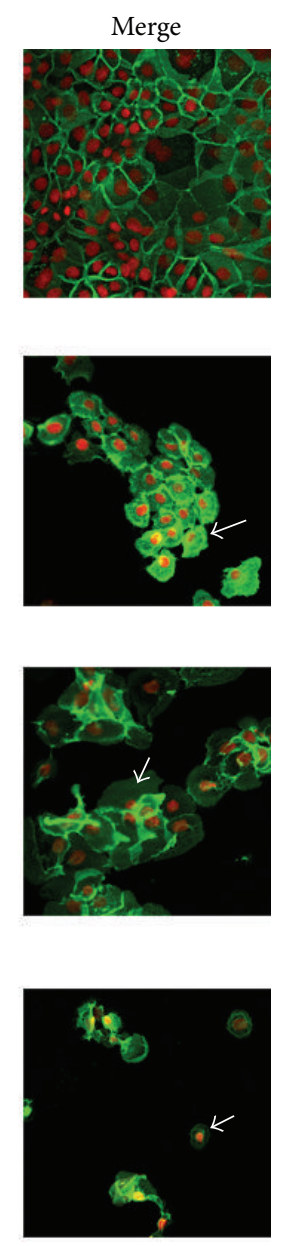

(F)

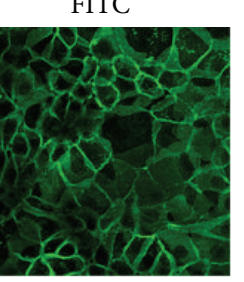

(E)

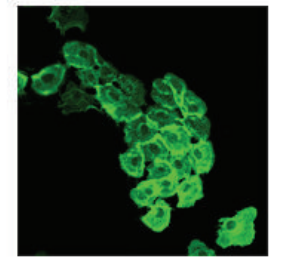

政 


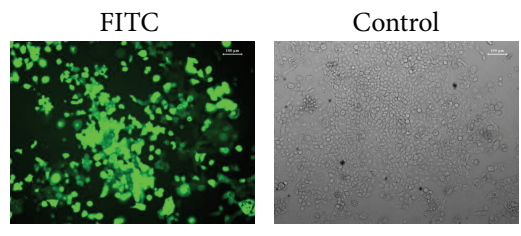

(A)
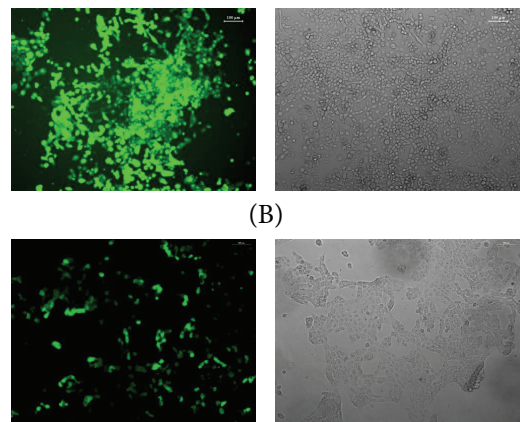

(B)
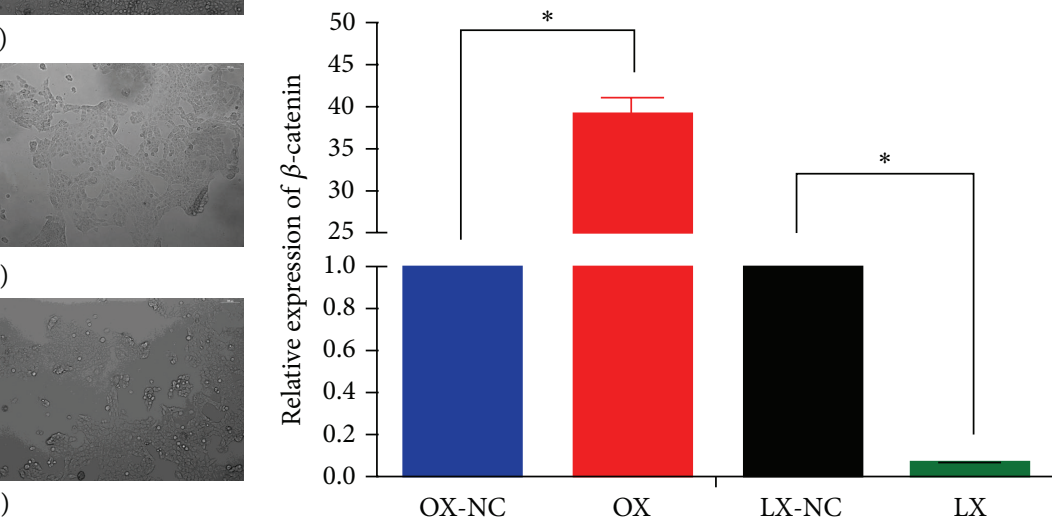

(D)

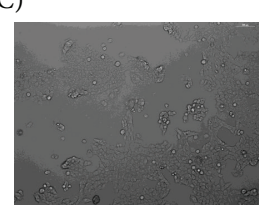

(a)

(b)

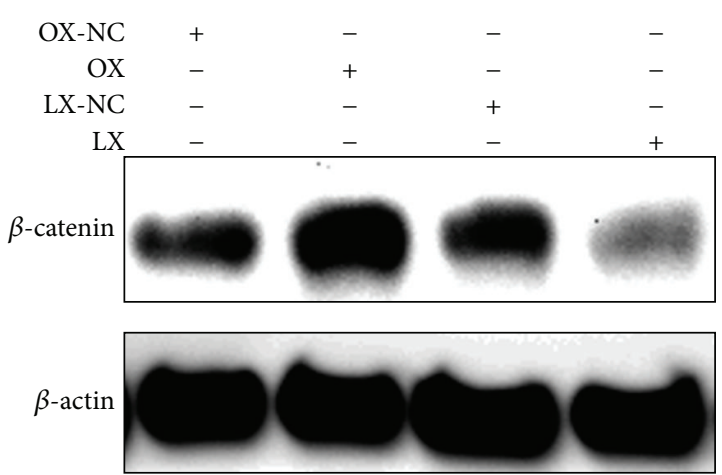

(c)

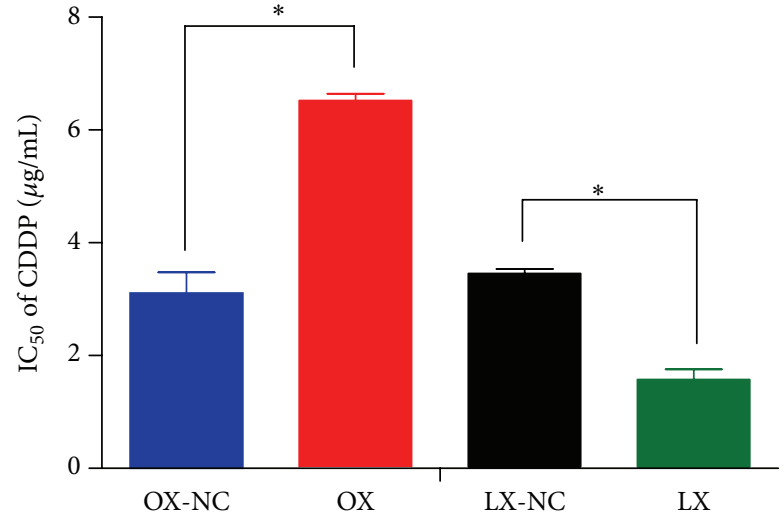

(d)

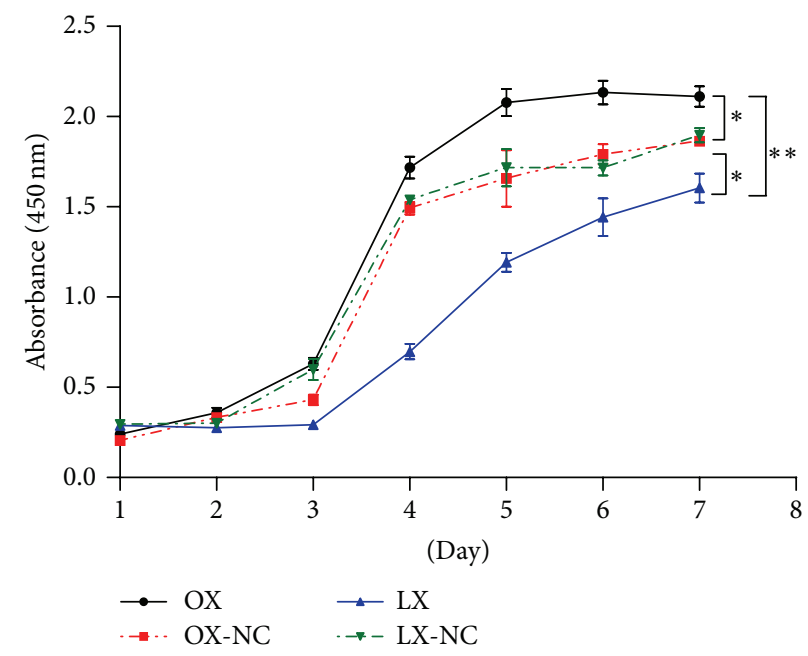

(e)

Figure 2: Continued. 

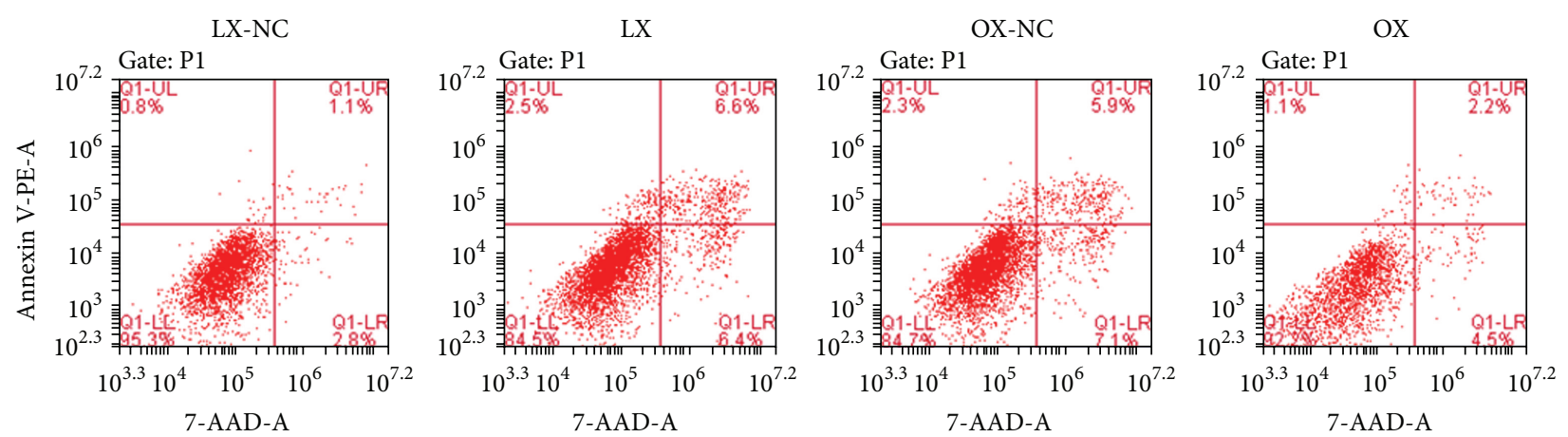

(A)

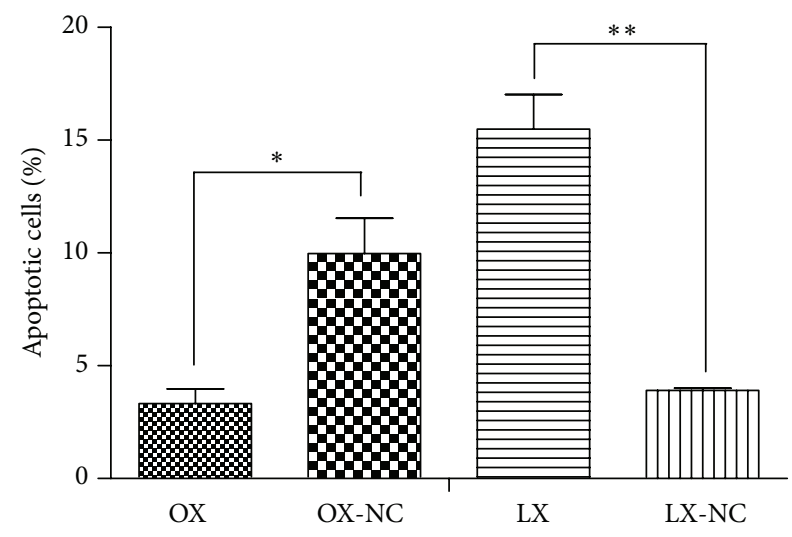

(B)

(f)

FIGURE 2: $\beta$-catenin knockdown promoted apoptosis and sensitivity to cisplatin but suppressed proliferation in SCC-25 cells. (a) Transfection efficiency of the cells was evaluated by the fluorescence microscopy (A: OX cells, B: OX-NC cells, C: LX cells, and D: LX-NC cells). (b) Gene expression of $\beta$-catenin was confirmed by PCR. (c) Protein expression of $\beta$-catenin was confirmed by Western blot analysis. (d) $\beta$ catenin knockdown caused a significant decrease in cisplatin $\mathrm{IC}_{50}$ of SCC- 25 cells. (e) CCK- 8 assay showed $\beta$-catenin knockdown suppressed proliferation in SCC-25 cells. (f) Flow cytometry analysis showed $\beta$-catenin knockdown promoted apoptosis (OX: overexpression, OX-NC: overexpression-negative control, LX: low expression, and LX-NC: low expression-negative control). ${ }^{*} P<0.05 ;{ }^{* *} P<0.01$ (magnification: 100x).

$\beta$-catenin translocated from the membrane to nucleus as the concentration of cisplatin increased (Figure 1(c)).

\subsection{Knockdown of $\beta$-Catenin Suppresses Cell Proliferation and} Enhances Sensitivity to Cisplatin in OSCC. We established stable cells lines with CTNNB1 knockin and knockdown by lentiviral transfection. Transfection efficiency was evaluated by fluorescence microscopy (Figure 2(a)). The efficiency of CTNNB1 knockin and knockdown was confirmed by PCR (Figure 2(b)) and Western blot analysis (Figure 2(c)). The $\mathrm{IC}_{50}$ values of cisplatin in the SCC-25 cells with CTNNB1 knockin and knockdown were evaluated by CCK8 assays. Our data showed that overexpression of $\beta$-catenin increased $\mathrm{IC}_{50}$ of cisplatin, whereas decreased expression of $\beta$-catenin led to decreased $\mathrm{IC}_{50}$ (Figure $2(\mathrm{~d})$ ). The proliferation and apoptosis assays showed cell proliferation and survival were significantly decreased $(P<0.05)$ in SCC-25 cells with CTNNB1 knockdown compared to the controls. Correspondingly, cell proliferation and survival were significantly increased in SCC-25 cells with CTNNB1 knockin after treatment with cisplatin (Figures 2(e) and 2(f)).

3.3. MRP-1, P-gp, Bcl-2, and Wnt Signaling Pathway Are Involved in $\beta$-Catenin-Mediated Cisplatin Chemoresistance. To determine the effects of $\beta$-catenin on chemotherapy, we examined the associated resistance proteins and resistance genes by Western blotting and RT-PCR. We found increased expression levels of Bcl-2, MRP-1, and MDR1 in SCC-25 cells with CTNNB1 knockin compared with the controls (Figure 3(a)). Conversely, we found decreased levels of Bcl-2, MRP-1, and MDR-1 in the SCC-25 cells with CTNNB1 knockdown. Moreover, Western blot analysis showed increased protein expression levels of Bcl-2, MRP-1, and P-gp in SCC-25 cells with CTNNB1 knockin compared with the controls. Expression levels of these proteins were decreased in the SCC-25 cells with CTNNB1 knockdown (Figure 3(b)). Therefore, overexpression of $\beta$-catenin in SCC25 cells may increase their resistance to cisplatin therapy, whereas decreased expression of $\beta$-catenin in SCC-25 cells 


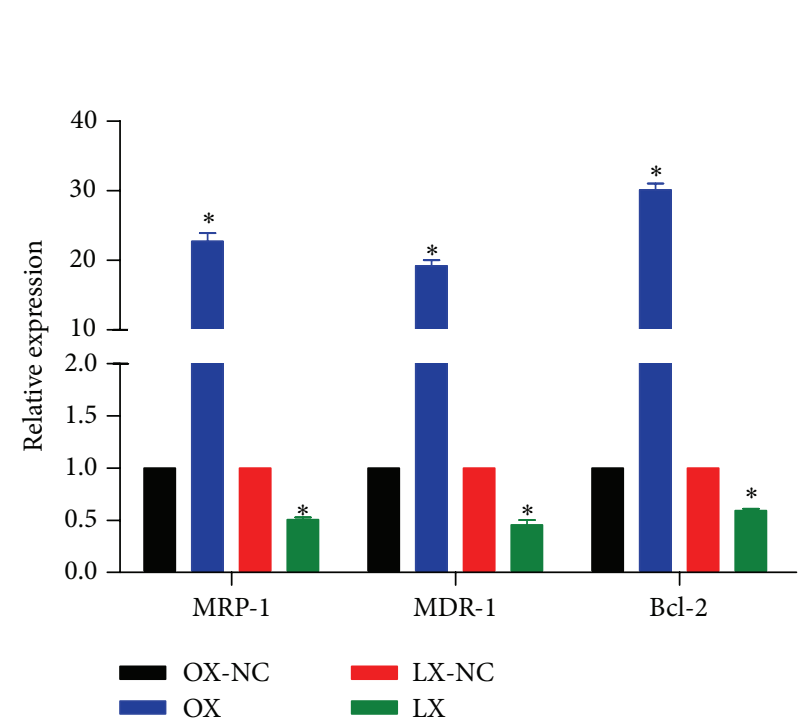

(a)

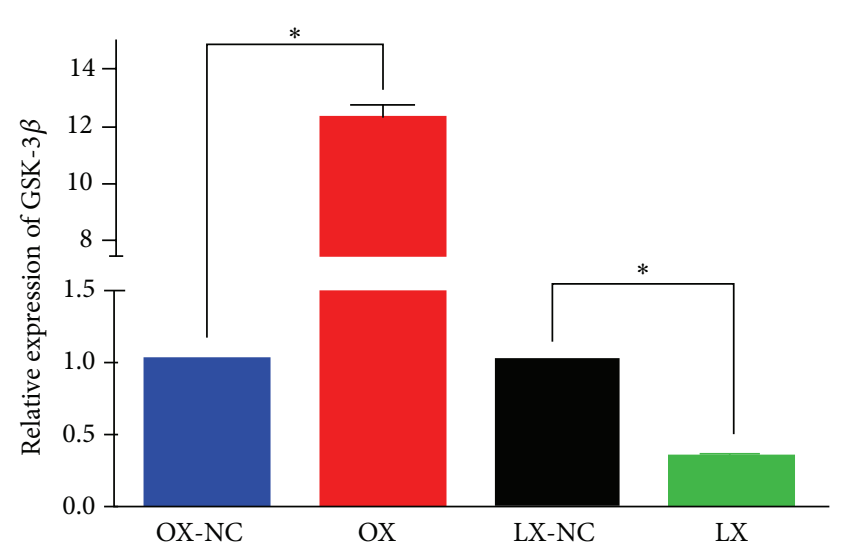

(c)

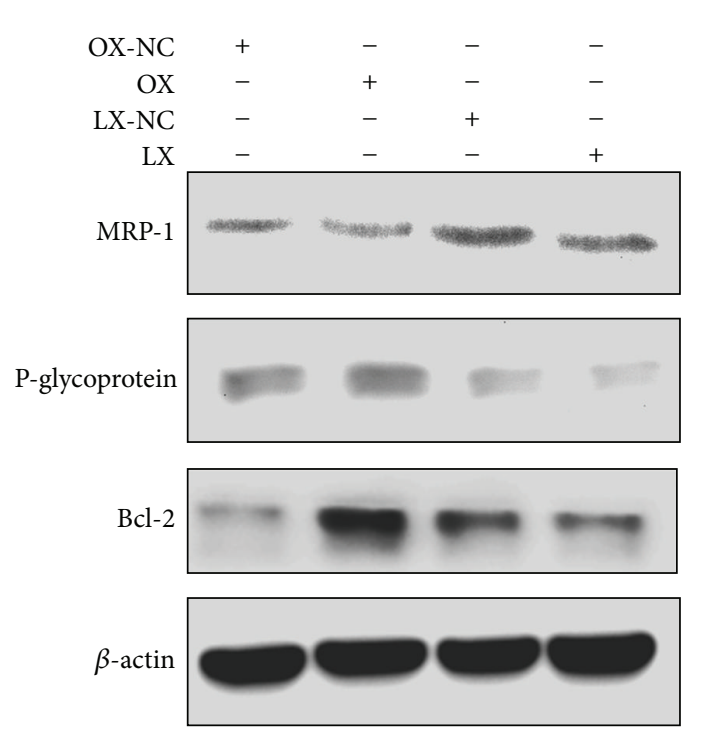

(b)

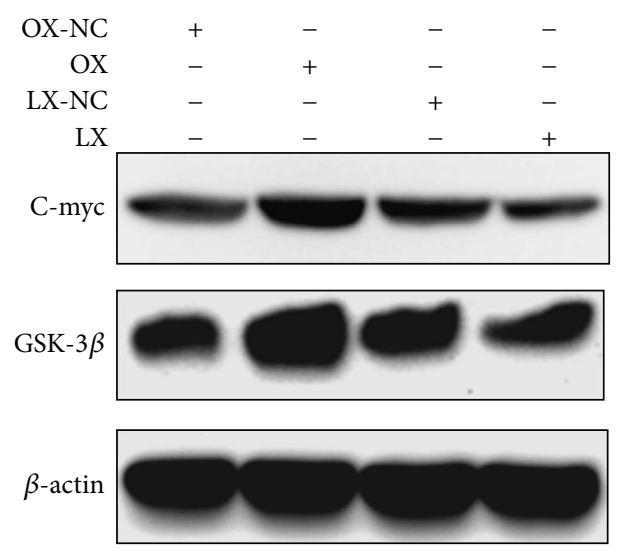

(d)

FIGURE 3: Overexpression of $\beta$-catenin increased the chemoresistance of SCC-25 cells to cisplatin and promoted cell survival. (a) Overexpression of $\beta$-catenin increased the expression levels of Bcl-2, MRP-1, and MDR-1 compared to the controls. (b) Western blot analysis of the protein expression levels of Bcl-2, MRP-1, and MDR-1. (c) Expression of $\beta$-catenin was involved in the Wnt signaling pathway by regulation of GSK-3 $\beta$ and C-myc. (d) Western blot analysis of the protein expression levels of GSK-3 $\beta$ and C-myc. ${ }^{*} P<0.05$.

may enhance their sensitivity to cisplatin. We further investigated the mechanisms involved in the chemoresistance of OSCC cells to cisplatin. We analyzed the expression levels of GSK-3 $\beta$ and C-myc in the two stable expression cell lines by RT-PCR (Figure 3(c)) and by Western blot analysis (Figure $3(\mathrm{~d})$ ) of the whole cell lysates. We found an increase in the expression levels of GSK-3 $\beta$ and C-myc in the SCC- 25 cells with CTNNB1 knockin compared with the controls. Conversely, we found a significant reduction in the expression levels of GSK-3 $\beta$ and C-myc in SCC- 25 cells with CTNNB1 knockdown compared with the controls. Thus, $\beta$ catenin could be involved in the activation of Wnt/ $\beta$-catenin signaling pathway through the regulation of GSK-3 $\beta$ and Cmyc.

3.4. Decreased Expression of $\beta$-Catenin in SCC-25 Cells Increases Cisplatin Sensitivity and Suppresses Tumor Formation in $B A L B / c$ Nude Mice. To evaluate the effect of $\beta$-catenin on cisplatin chemotherapy, SCC-25 cells with CTNNB1 knockin or knockdown were implanted subcutaneously into left posterior flanks of BALB/c nude mice. Individual tumors from mice treated with cisplatin were collected and weighed. The average tumor volume of the CTNNB1 knockdown group was significantly smaller than those from the control group (Figure 4(a)), which showed that the tumor formation was suppressed in the cisplatin-treated group with CTNNB1 knockdown (Figure 4(b)). In addition, the average tumor weight was markedly reduced compared with the $\beta$-catenin overexpression or control groups (Figure 4(c)). Conversely, the overexpression of $\beta$-catenin in the cisplatin-treated mice promoted tumor formation with continuous increase of the tumor size compared to the other groups, which indicated overexpression of $\beta$-catenin promoted chemoresistance. These results provide evidence that knockdown of $\beta$-catenin in OSCC cells may enhance their sensitivity to cisplatin and reduce the tumor growth in vivo. 

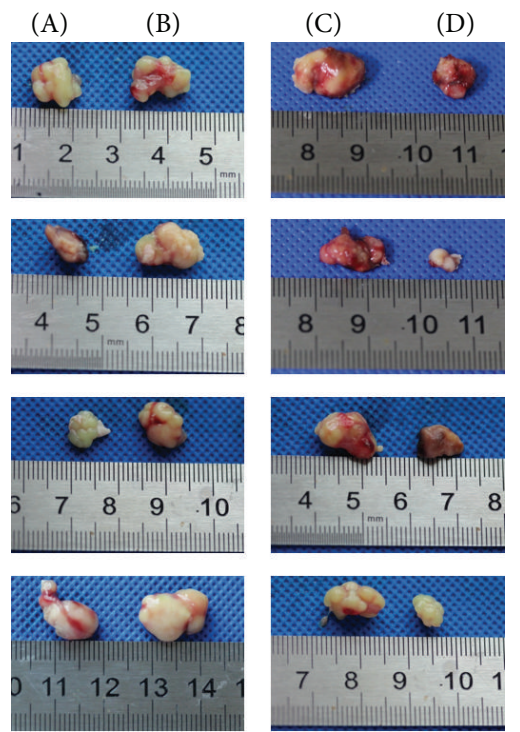

(a)

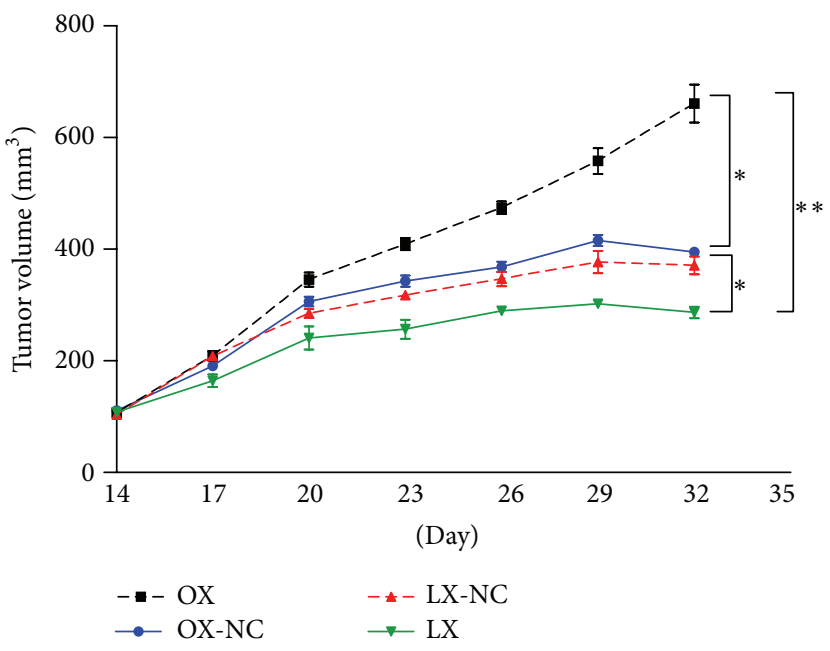

(b)

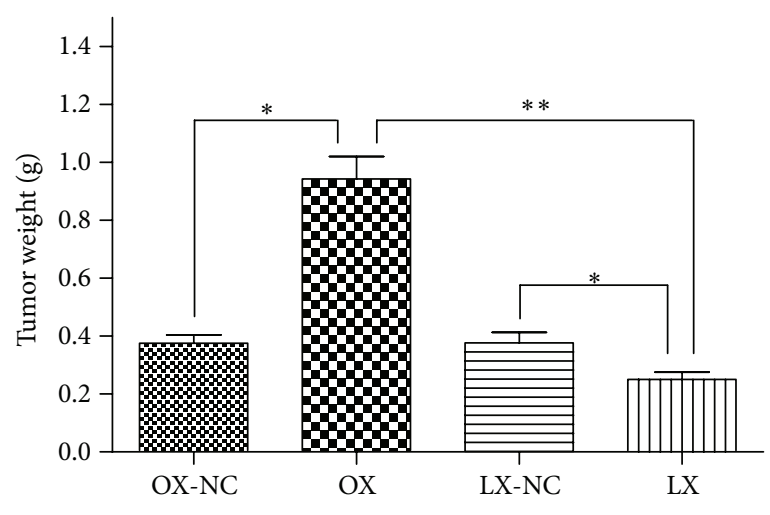

(c)

FIGURE 4: $\beta$-catenin knockdown increased sensitivity to cisplatin in vivo. (a) Photographs of tumors (A: OX-NC, B: OX, C: LX-NC, and D: LX). (b) Tumor sizes were measured from day 14 until mice were killed. When tumor volumes reached 100 to $150 \mathrm{~mm}^{3}, \mathrm{mice}^{\mathrm{s}}$ were injected with $4 \mathrm{mg} / \mathrm{kg}$ cisplatin through the tail vein. (c) Tumor weight was measured at the end of the experiment. The tumor weight was significantly reduced in mice treated with OSCC cells with $\beta$-catenin knockdown after cisplatin treatment, whereas the tumor size continuously increased with the overexpression of $\beta$-catenin indicating promoted tumor growth. ${ }^{*} P<0.05 ;{ }^{* *} P<0.01$.

\section{Discussion}

Recent accumulating evidence has supported the notion that $\mathrm{Wnt} / \beta$-catenin signaling is associated with resistance to chemotherapy in several cancers $[25,26]$. Our findings showed higher expression levels of $\beta$-catenin were found in specimens from patients who had received cisplatin chemotherapy compared to those who had not received chemotherapy [23], which was confirmed in human OSCC cell lines treated with cisplatin. In these treatment groups, the expression levels of $\beta$-catenin were found to be increased in a concentration- and time-dependent manner with the cisplatin treatment. We also observed nuclear translocation of $\beta$-catenin in cisplatin-treated groups by confocal microscopy and Western blot analysis. These results provide strong evidence that $\beta$-catenin plays an essential role in cisplatinmediated resistance in OSCC. However, the molecular mechanisms of drug resistance and the relationship with abnormal expression of $\beta$-catenin in OSCC have not been clearly defined.

Several mechanisms of cisplatin resistance have been extensively reported [27], involving reduced cisplatin uptake and accumulation, activation of DNA repair mechanisms and decreased DNA mismatch repair [28], apoptosis inhibition and reduced apoptotic response [29], and cell signaling molecules and pathways [30]. Our results showed overexpression of $\beta$-catenin in OSCC cells led to a higher cisplatin 
$\mathrm{IC}_{50}$ after $24 \mathrm{~h}$ of treatment $(P<0.05)$ compared to reduced expression of $\beta$-catenin in OSCC cells. $\beta$-catenin was reported to be involved in chemoresistance/radioresistance in colon cancer cells [31]. Conversely, we found decreased expression of $\beta$-catenin in OSCC cells suppressed cell proliferation and promoted apoptosis, making the cells more sensitive to cisplatin, which was also confirmed in our animal study results. $\beta$-catenin is an important adhesion molecule and a key regulator in Wnt signaling pathway. Wnt/ $\beta$-catenin signaling pathway has been shown to be involved in cisplatin resistance through the regulation of $\beta$-catenin. Upregulation of $\beta$-catenin expression in SCC-25 cells led to an overexpression of GSK-3 $\beta$ and C-myc [32], whereas downregulation of $\beta$-catenin expression led to lower expression levels of GSK$3 \beta$ and C-myc. Both GSK-3 $\beta$ and $\beta$-catenin are two key regulators in $\mathrm{Wnt} / \beta$-catenin signaling pathway involved in the regulation of cell growth and adhesion. In the absence of Wnt signaling, $\beta$-catenin is phosphorylated by GSK- $3 \beta$ and targeted for degradation [33]. Activation of Wnt signaling prevents $\beta$-catenin from being phosphorylated by GSK$3 \beta$, resulting in its nuclear translocation $[34,35]$. In our present study, $\beta$-catenin translocated and accumulated in the nucleus in OSCC cells treated with cisplatin. Accumulation of nuclear $\beta$-catenin and the subsequent binding to Tcf transcription factors [36] promoted the overexpression of downstream target genes, such as C-myc, which we also observed in our results. Moreover, C-myc has been reported to be overexpressed in cisplatin resistance [32]. The abnormal expression of downstream target genes can lead to abnormal proliferation of tumor cells and the increased ability of cancer cells to evade apoptosis [37] allowing them to develop cisplatin resistance [38]. Bcl-2 is an antiapoptotic protein of the $\mathrm{Bcl}-2$ family that is involved in chemotherapy $[39,40]$. We found increased expression levels of Bcl-2 in OSCC cells overexpressing $\beta$-catenin. Moreover, evidence suggests that overexpression of $\mathrm{Bcl}-2$ in tumor cells can result in their escape from cell apoptosis and resistance to anticancer drugs [41]. Conversely, it was reported that low expression levels of Bcl-2 could promote apoptosis of OSCC cells [42], which was consistent with our results. In addition, we found overexpression of $\beta$-catenin in SCC-25 cells led to higher expression levels of P-gp and MRP-1, whereas the reverse was true with reduced expression of $\beta$-catenin compared with the control cells. Substantial evidence suggests that P-gp [43] and MRP-1 [44] are associated with multidrug resistance in several types of advanced cancer. Elevated levels of P-gp and MRP-1 have been reported in cancer cells showing an acquired multidrugresistant phenotype following chemotherapy, whereas low levels of P-gp and MRP-1 were observed in cancer cells before chemotherapy $[45,46]$.

In conclusion, our findings revealed that overexpression of $\beta$-catenin was associated with cisplatin resistance in OSCC cells and that reduced expression of $\beta$-catenin could confer sensitivity to cisplatin resulting in better treatment efficacy. However, the precise molecular mechanisms and clinical significance of our findings need to be further investigated. Our results demonstrated that $\beta$-catenin might play important roles in cisplatin resistance in OSCC through the regulatory mechanisms of Wnt/ $\beta$-catenin signaling pathway. Therefore, a thorough understanding of molecular mechanism involving $\beta$-catenin would enable the development of novel strategies to overcome possible drug resistance.

\section{Competing Interests}

The authors declare that they have no competing interests.

\section{Authors' Contributions}

Long Li and Hai-Chao Liu contributed equally to this work.

\section{Acknowledgments}

This study was supported by the National Natural Science Foundation of China (Grant no. 81272949).

\section{References}

[1] J. Ferlay, I. Soerjomataram, R. Dikshit et al., "Cancer incidence and mortality worldwide: Sources, methods and major patterns in GLOBOCAN 2012," International Journal of Cancer, vol. 136, no. 5, pp. E359-E386, 2015.

[2] J.-P. Machiels, M. Lambrecht, F.-X. Hanin et al., "Advances in the management of squamous cell carcinoma of the head and neck," F1000Prime Reports, vol. 6, article 44, 2014.

[3] R. I. Haddad and D. M. Shin, "Recent advances in head and neck cancer," New England Journal of Medicine, vol. 359, no. 11, pp. 1096-1154, 2008

[4] A. Argiris, M. V. Karamouzis, D. Raben, and R. L. Ferris, "Head and neck cancer," The Lancet, vol. 371, no. 9625, pp. 1695-1709, 2008.

[5] D. M. Parkin, F. Bray, J. Ferlay, and P. Pisani, "Estimating the world cancer burden: Globocan 2000," International Journal of Cancer, vol. 94, no. 2, pp. 153-156, 2001.

[6] I. Chiba, "Prevention of betel quid chewers' oral cancer in the asian-pacific area," Asian Pacific Journal of Cancer Prevention, vol. 2, no. 4, pp. 263-269, 2001.

[7] J. Ferlay, H.-R. Shin, F. Bray, D. Forman, C. D. Mathers, and D. M. Parkin, "Estimates of worldwide burden of cancer in 2008: GLOBOCAN 2008," International Journal of Cancer, vol. 127, no. 12, pp. 2893-2917, 2010.

[8] R. Siegel, E. Ward, O. Brawley, and A. Jemal, "Cancer statistics, 2011: the impact of eliminating socioeconomic and racial disparities on premature cancer deaths," CA Cancer Journal for Clinicians, vol. 61, no. 4, pp. 212-236, 2011.

[9] A. Jemal, R. Siegel, E. Ward, Y. Hao, J. Xu, and M. J. Thun, "Cancer statistics, 2009," CA: A Cancer Journal for Clinicians, vol. 59, no. 4, pp. 225-249, 2009.

[10] J.-P. Pignon, A. le Maître, E. Maillard, and J. Bourhis, "Metaanalysis of chemotherapy in head and neck cancer (MACHNC): an update on 93 randomised trials and 17,346 patients," Radiotherapy and Oncology, vol. 92, no. 1, pp. 4-14, 2009.

[11] D. P. Kelsen, K. A. Winter, L. L. Gunderson et al., "Long-term results of RTOG trial 8911 (USA Intergroup 113): a random assignment trial comparison of chemotherapy followed by surgery compared with surgery alone for esophageal cancer," Journal of Clinical Oncology, vol. 25, no. 24, pp. 3719-3725, 2007.

[12] E. Ancona, A. Ruol, C. Castoro et al., "First-line chemotherapy improves the resection rate and long-term survival of locally 
advanced (T4, any N, M0) squamous cell carcinoma of the thoracic esophagus: final report on 163 consecutive patients with 5-year follow-up," Annals of Surgery, vol. 226, no. 6, pp. 714-724, 1997.

[13] C. Domenge, C. Hill, J. L. Lefebvre et al., "Randomized trial of neoadjuvant chemotherapy in oropharyngeal carcinoma. French Groupe d'Etude des Tumeurs de la Tete et du Cou (GETTEC)," British Journal of Cancer, vol. 83, pp. 1594-1598, 2000.

[14] J. Bernier, C. Domenge, M. Ozsahin et al., "Postoperative irradiation with or without concomitant chemotherapy for locally advanced head and neck cancer," The New England Journal of Medicine, vol. 350, no. 19, pp. 1945-1952, 2004.

[15] J. S. Cooper, T. F. Pajak, A. A. Forastiere et al., "Postoperative concurrent radiotherapy and chemotherapy for high-risk squamous-cell carcinoma of the head and neck," The New England Journal of Medicine, vol. 350, no. 19, pp. 1937-2019, 2004.

[16] Y. Yu, G. Ramena, and R. C. Elble, "The role of cancer stem cells in relapse of solid tumors," Frontiers in Bioscience-Elite, vol. 4, no. 4, pp. 1528-1541, 2012.

[17] D. Wang and S. J. Lippard, "Cellular processing of platinum anticancer drugs," Nature Reviews Drug Discovery, vol. 4, no. 4, pp. 307-320, 2005.

[18] S. Yoshioka, M. L. King, S. Ran et al., "WNT7A regulates tumor growth and progression in ovarian cancer through the WNT/ $\beta$ catenin pathway," Molecular Cancer Research, vol. 10, no. 3, pp. 469-482, 2012.

[19] D. J. Stewart, "Mechanisms of resistance to cisplatin and carboplatin," Critical Reviews in Oncology/Hematology, vol. 63, no. 1, pp. 12-31, 2007.

[20] R. C. Arend, A. I. Londoño-Joshi, J. M. Straughn Jr., and D. J. Buchsbaum, "The Wnt/ $\beta$-catenin pathway in ovarian cancer: a review," Gynecologic Oncology, vol. 131, no. 3, pp. 772-779, 2013.

[21] J. Yeung, M. T. Esposito, A. Gandillet et al., “ $\beta$-Catenin mediates the establishment and drug resistance of MLL leukemic stem cells," Cancer Cell, vol. 18, no. 6, pp. 606-618, 2010.

[22] R. C. Arend, A. I. Londoño-Joshi, R. S. Samant et al., "Inhibition of Wnt/ $\beta$-catenin pathway by niclosamide: a therapeutic target for ovarian cancer," Gynecologic Oncology, vol. 134, no. 1, pp. 112120, 2014.

[23] B. Zhang, M. Liu, H.-K. Tang et al., "The expression and significance of MRP1, LRP, TOPOII $\beta$, and BCL2 in tongue squamous cell carcinoma," Journal of Oral Pathology and Medicine, vol. 41, no. 2, pp. 141-148, 2012.

[24] L. Lü, L. Zhang, M. S. M. Wai, D. T. W. Yew, and J. Xu, "Exocytosis of MTT formazan could exacerbate cell injury," Toxicology in Vitro, vol. 26, no. 4, pp. 636-644, 2012.

[25] M. Flahaut, R. Meier, A. Coulon et al., “The Wnt receptor FZD1 mediates chemoresistance in neuroblastoma through activation of the Wnt/ $\beta$-catenin pathway," Oncogene, vol. 28, no. 23, pp. 2245-2256, 2009.

[26] T. Ohigashi, R. Mizuno, J. Nakashima, K. Marumo, and M. Murai, "Inhibition of Wnt signaling downregulates Akt activity and induces chemosensitivity in PTEN-mutated prostate cancer cells," Prostate, vol. 62, no. 1, pp. 61-68, 2005.

[27] H. J. Broxterman, J. Lankelma, and K. Hoekman, "Resistance to cytotoxic and anti-angiogenic anticancer agents: similarities and differences," Drug Resistance Updates, vol. 6, no. 3, pp. 111127, 2003.
[28] E. R. Jamieson and S. J. Lippard, "Structure, recognition, and processing of cisplatin-DNA adducts," Chemical Reviews, vol. 99, no. 9, pp. 2467-2498, 1999.

[29] N. Eckstein, K. Servan, B. Hildebrandt et al., "Hyperactivation of the insulin-like growth factor receptor I signaling pathway Is an essential event for cisplatin resistance of ovarian cancer cells," Cancer Research, vol. 69, no. 7, pp. 2996-3003, 2009.

[30] K. Kohno, T. Uchiumi, I. Niina et al., "Transcription factors and drug resistance," European Journal of Cancer, vol. 41, no. 16, pp. 2577-2586, 2005.

[31] N. Chikazawa, H. Tanaka, T. Tasaka et al., "Inhibition of Wnt signaling pathway decreases chemotherapy-resistant sidepopulation colon cancer cells," Anticancer Research, vol. 30, no. 6, pp. 2041-2048, 2010.

[32] Z. H. Siddik, "Cisplatin: mode of cytotoxic action and molecular basis of resistance," Oncogene, vol. 22, no. 47, pp. 7265-7279, 2003.

[33] M. T. Furlong and P. J. Morin, "Rare activation of the TCF/ $\beta$ catenin pathway in ovarian cancer," Gynecologic Oncology, vol. 77, no. 1, pp. 97-104, 2000.

[34] S. M. Sillanpää, M. A. Anttila, K. A. Voutilainen et al., "Prognostic significance of matrix metalloproteinase-7 in epithelial ovarian cancer and its relation to $\beta$-catenin expression," International Journal of Cancer, vol. 119, no. 8, pp. 1792-1799, 2006.

[35] S. Condello, C. A. Morgan, S. Nagdas et al., " $\beta$-Cateninregulated ALDH1A1 is a target in ovarian cancer spheroids," Oncogene, vol. 34, no. 18, pp. 2297-2308, 2015.

[36] M. Van Noort and H. Clevers, "TCF transcription factors, mediators of Wnt-signaling in development and cancer," Developmental Biology, vol. 244, no. 1, pp. 1-8, 2002.

[37] C. G. Ferreira, M. Epping, F. A. Kruyt, and G. Giaccone, "Apoptosis: target of cancer therapy," Clinical Cancer Research, vol. 8, no. 7, pp. 2024-2034, 2003.

[38] Y. Zhang, B. Z. Liu, Q. Y. Zhao, T. Hou, and X. Huang, "Nuclear localizaiton of $\beta$-catenin is associated with poor survival and chemo-/radioresistance in human cervical squamous cell cancer," International Journal of Clinical and Experimental Pathology, vol. 7, no. 7, pp. 3908-3917, 2014.

[39] D.-F. Yu, F.-R. Wu, Y. Liu, H. Liu, and Q. Xia, "Bcl-2 gene silence enhances the sensitivity toward 5-Fluorouracil in gastric adenocarcinoma cells," Biomedicine and Pharmacotherapy, vol. 67, no. 7, pp. 615-619, 2013.

[40] H. V. Jagani, V. R. Josyula, V. R. Palanimuthu, R. C. Hariharapura, and S. S. Gang, "Improvement of therapeutic efficacy of PLGA nanoformulation of siRNA targeting anti-apoptotic Bcl-2 through chitosan coating," European Journal of Pharmaceutical Sciences, vol. 48, no. 4-5, pp. 611-618, 2013.

[41] R. J. Youle and A. Strasser, "The BCL-2 protein family: opposing activities that mediate cell death," Nature Reviews Molecular Cell Biology, vol. 9, no. 1, pp. 47-59, 2008.

[42] K. Kato, S. Kawashiri, K. Yoshizawa, H. Kitahara, and E. Yamamoto, "Apoptosis-associated markers and clinical outcome in human oral squamous cell carcinomas," Journal of Oral Pathology and Medicine, vol. 37, no. 6, pp. 364-371, 2008.

[43] F. J. Sharom, "The P-glycoprotein efflux pump: how does it transport drugs?" Journal of Membrane Biology, vol. 160, no. 3, pp. 161-175, 1997.

[44] E. M. Leslie, R. G. Deeley, and S. P. C. Cole, "Toxicological relevance of the multidrug resistance protein $1, \mathrm{MRP} 1$ (ABCC1) and related transporters," Toxicology, vol. 167, no. 1, pp. 3-23, 2001. 
[45] V. Velingkar and V. Dandekar, "Modulation of P-glycoprotein mediated multidrug resistance (MDR) in cancer using chemosensitizers," International Journal of Pharmaceutical Sciences and Research, vol. 1, pp. 104-111, 2010.

[46] T. Ozben, "Mechanisms and strategies to overcome multiple drug resistance in cancer," FEBS Letters, vol. 580, no. 12, pp. 2903-2909, 2006. 


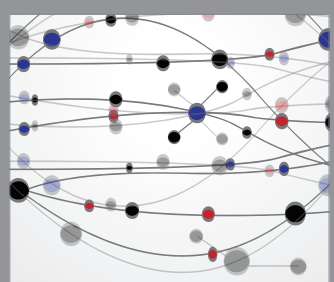

The Scientific World Journal
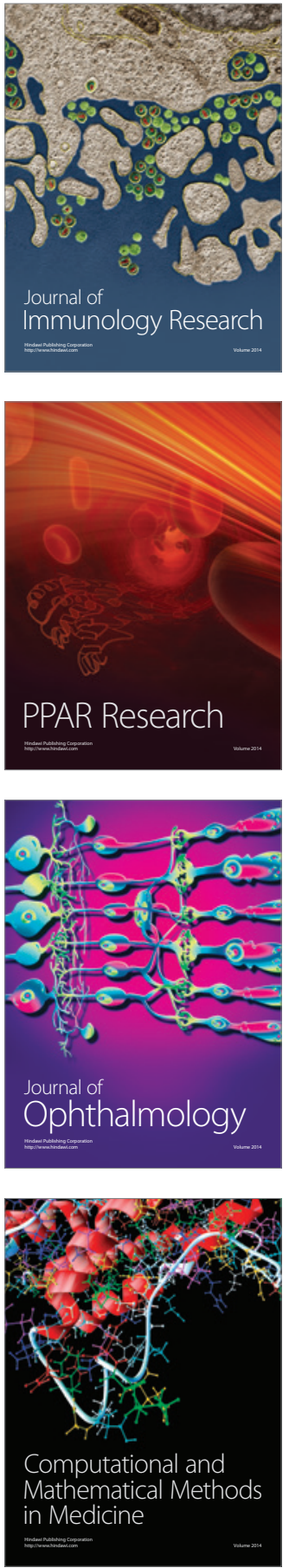

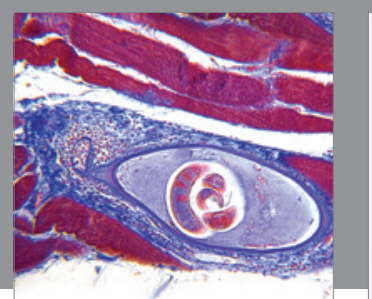

Gastroenterology Research and Practice

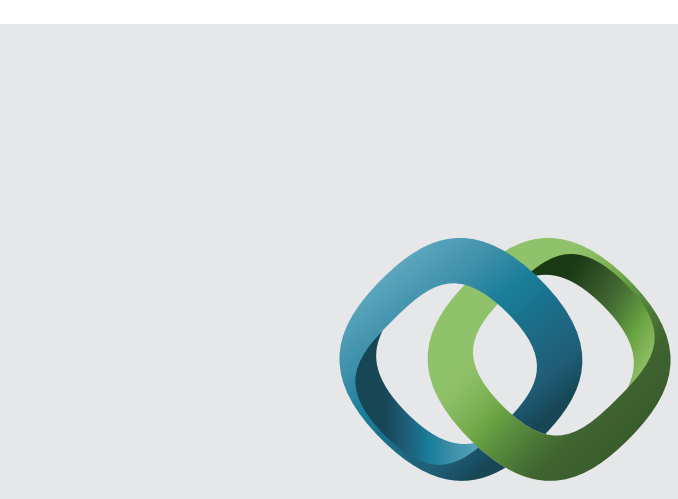

\section{Hindawi}

Submit your manuscripts at

http://www.hindawi.com
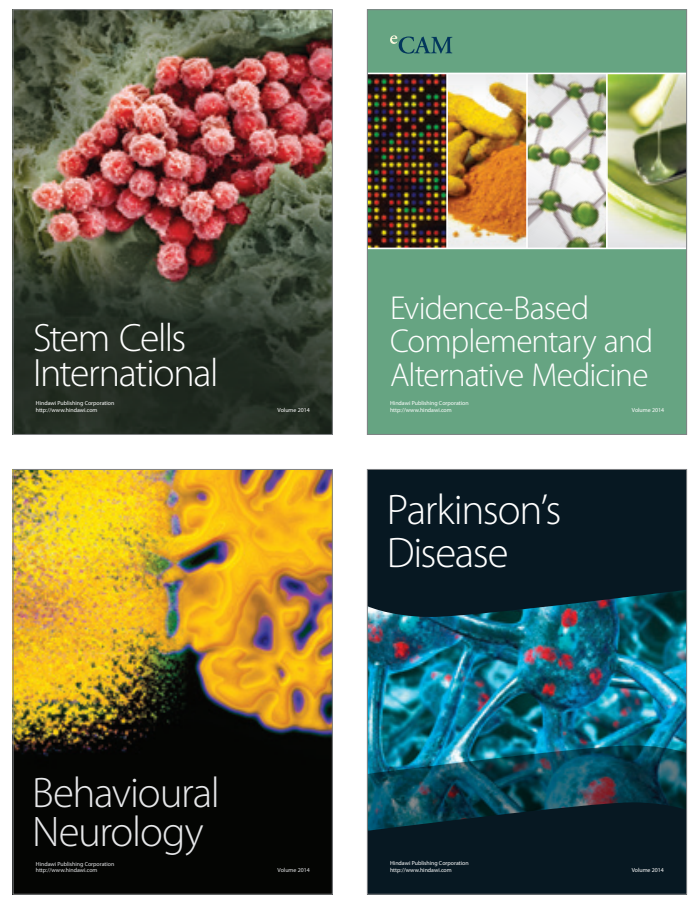
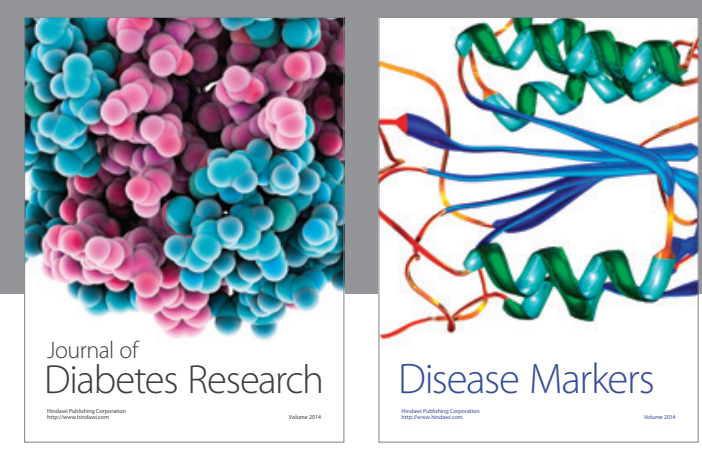

Disease Markers
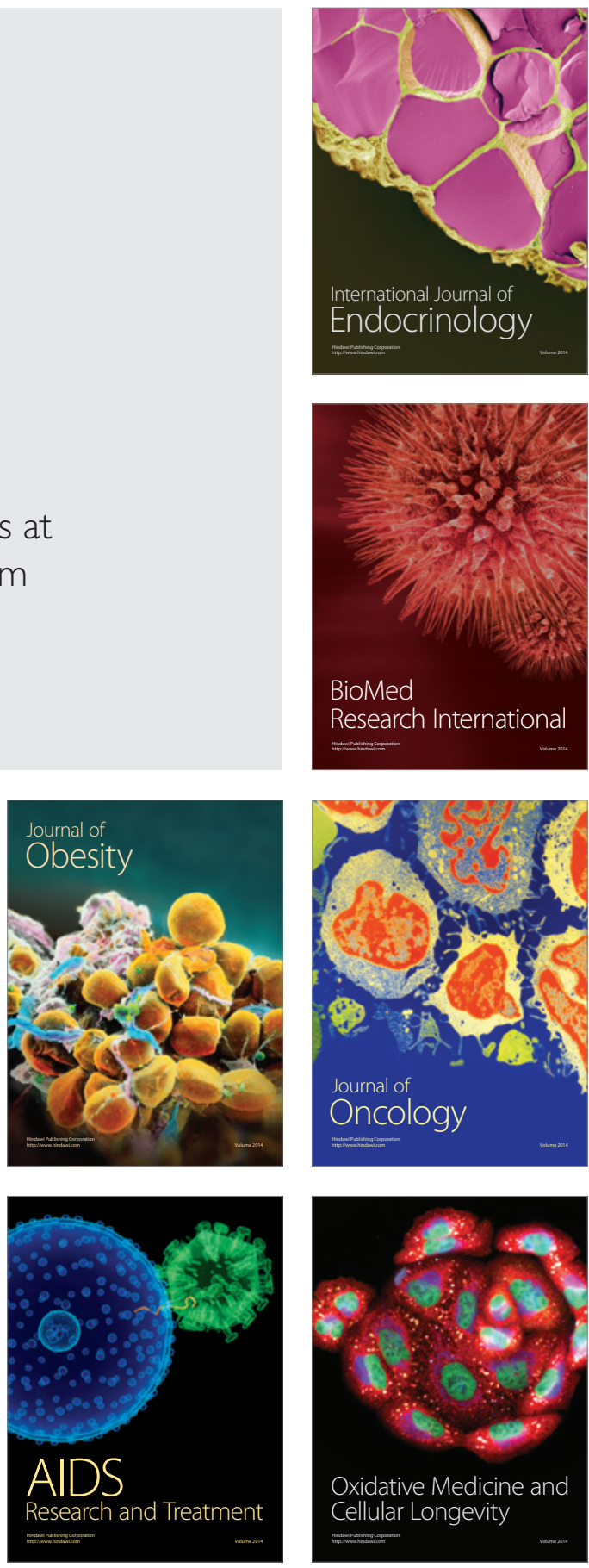